\title{
PERANCANGAN STASIUN KERJA PENGGORENGAN ERGONOMIS DI UMKM CEMILAN KERIPIK DESA KRANGGAN TANGSEL
}

\author{
Agustina Christiani, Priskila Christine Rahayu, Rudy Vernando Silalahi, Eric Jobiliong, \\ Laurence, Ardian Chandra \\ Program Studi Teknik Industri, Fakultas Sains dan Teknologi, Universitas Pelita Harapan \\ agustina.christiani@uph.edu,priskila.christine@uph.edu,rudy.silalahi@uph.edu, eric.jobiliong@uph.edu, \\ laurence.fti@uph.edu, ardianchandra2@gmail.com
}

\begin{abstract}
Abstrak
Kegiatan PkM ini adalah kelanjutan dari kegiatan PKM tentang Business Mentoring di UMKM Cemilan Keripik milik Ibu Supiyah yang terletak di Desa Kranggan Tangerang Selatan. Kegiatan PkM di UMKM tersebut sudah dirintis sejak tahun 2018. Di UMKM Cemilan Keripik ini diproduksi berbagai macam keripik dan makanan ringan. Permasalahan yang dihadapi di UMKM ini adalah para pekerja khususnya di bagian penggorengan keripik pisang mengalami sakit punggung karena harus duduk di atas kotak kayu selama kurang lebih 5- 6 jam sehari. Hasil analisis menggunakan Rapid Upper Limb Assessment (RULA) untuk postur kerja awal, diketahui memiliki skor akhir sebesar 5-7. Hal ini berarti postur kerja tersebut membahayakan pekerja. Berdasarkan permasalahan tersebut sudah dirancang dan dibuat stasiun kerja baru berupa meja dan kursi yang ergonomis, agar pekerja dapat melakukan pekerjaannya dengan lebih aman dan nyaman. Dengan adanya stasiun kerja baru tersebut, skor RULA turun menjadi 3 yang berarti postur kerja yang baru lebih aman bagi pekerja.
\end{abstract}

Kata Kunci : stasiun penggorengan, RULA, meja dan kursi ergonomis

\section{PENDAHULUAN}

Desa Kranggan yang terletak di Kecamatan Setu merupakan salah satu Sentra Pengolahan Industri Rumah Tangga yang dibentuk oleh Pemerintah Kota Tangerang Selatan. Saat ini jumlah UMKM yang ada di wilayah ini sudah mencapai 200 UMKM. Salah satu UMKM yang ada adalah UMKM pembuatan cemilan keripik yang dimiliki oleh Ibu Supiyah. UMKM tersebut telah berdiri sejak tahun 2012 (sudah beroperasi selama kira-kira 7 tahun).

Kegiatan PkM ini merupakan kelanjutan dari PkM sebelumnya, dimana telah dilakukan kegiatan business mentoring untuk meningkatkan kualitas dan kuantitas produksi serta sistem pemasaran produk keripik dan kue kembang goyang. Berdasarkan hasil observasi dan wawancara dengan beberapa pekerja diketahui terdapat permasalahan yaitu adanya keluhan berupa sakit pinggang dan sakit punggung. Hal ini disebabkan karena pekerja menggoreng keripik dalam posisi duduk di atas kotak untuk jangka waktu lama (dapat mencapai 6 jam sehari). Postur kerja dapat dilihat pada gambar 1. 


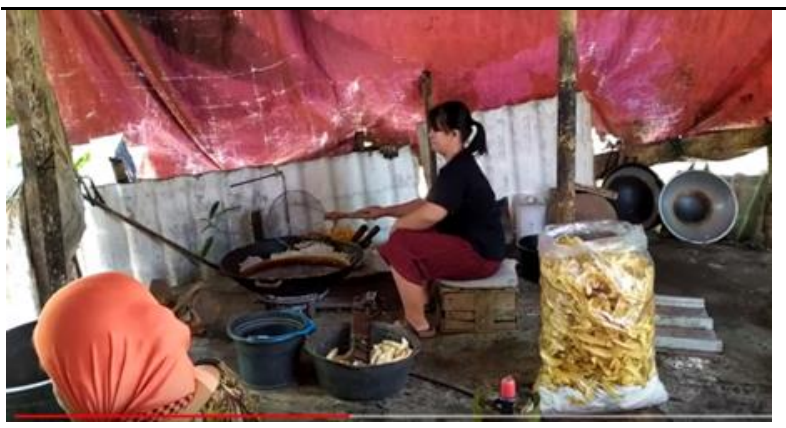

Gambar 1. Postur kerja bagian penggorengan keripik

Work-related Musculoskeletal Disorders (WMSD) adalah penyakit yang terkait dan/atau diperburuk oleh pekerjaan yang dapat mempengaruhi ekstremitas atas, area punggung bawah, dan ekstremitas bawah (Nunes dan Bush, 2012). Beberapa rekomendasi telah dikembangkan untuk desain dan penataan stasiun kerja, serta penggunaan alat dan perlengkapan yang pada akhirnya dapat meringankan atau mengurangi WMSD (McCauley Bush, 2011).

Salah satu metode untuk menganalisis risiko WMSD pada pekerja adalah metode RULA (Rapid Upper Limb Assessment). Metode RULA biasanya digunakan untuk menganalisis pekerjaan yang berpotensi menimbulkan cedera pada anggota gerak atas. Beberapa penelitian terdahulu (Dzikrillah dan Yuliani, 2015; Wijaya dan Muhsin, 2018; Bintang \& Dewi, 2017) menggunakan metode RULA untuk menganalisis dan memperbaiki postur kerja pada berbagai industri.

Berdasarkan permasalahan yang dihadapi oleh pekerja di UMKM Cemilan Keripik ini, maka dalam kegiatan PkM ini akan dianalisis postur kerja pekerja stasiun penggorengan menggunakan metode RULA. Untuk memperbaiki postur kerja juga dirancang dan dibuat stasiun kerja yang terdiri dari meja dan kursi kerja yang ergonomis untuk proses penggorengan, sehingga pekerja dapat bekerja lebih nyaman, dan pada akhirnya dapat meningkatkan produktivitas pekerja.

\section{METODE}

Tahapan pelaksanaan kegiatan PKM mengikuti metode penelitian terdahulu (Christiani et al, 2019), yang terdiri atas 5 tahap. Tahap pertama yaitu melakukan survei ke lokasi PkM untuk mengumpulkan data awal, melalui wawancara untuk mengetahui kebutuhan pekerja akan rancangan stasiun/tempat kerja yang baru. Juga dilakukan pengukuran stasiun kerja yang lama (ukuran kompor/tungku, bangku/boks, kuali, wadah bahan baku dan wadah produk). Tahap kedua mencakup analisis postur kerja sekarang menggunakan RULA untuk mengetahui level risiko musculoskeletal disorder (McAtamney dan Corlett, 1993).

Tahap ketiga meliputi perancangan stasiun kerja berdasarkan metode yang dikembangkan oleh Ulrich dan Eppinger (2012). Pada tahap ini dilakukan wawancara kepada para pekerja untuk mendapatkan voice of customer tentang stasiun kerja (berupa meja dan kursi kerja) yang dibutuhkan. Kemudian dibuat House of Quality atau $\mathrm{HoQ}$ (Shrivastava, 2016) untuk mendapatkan spesifikasi teknis dari meja dan kursi kerja tersebut. Tahap selanjutnya adalah dikembangkan alternatifalternatif rancangan meja dan kursi kerja. Berikutnya adalah pemilihan rancangan stasiun kerja. Setelah itu dilakukan pengukuran data antropometri pekerja untuk menentukan ukuran meja dan kursi kerja (Chuan, Hartono dan Kumar, 2010).

Tahap keempat yaitu pembuatan stasiun kerja berdasarkan rancangan yang dipilih. Rancangan stasiun kerja terpilih dibawa ke bengkel las untuk dibuat menjadi meja dan kursi kerja. Tahap kelima mencakup serah terima stasiun kerja dan melakukan pelatihan cara penggunaan stasiun kerja yang baru. Kemudian dilakukan uji coba/simulasi postur kerja dengan stasiun kerja yang baru serta dilakukan analisis postur kerja baru menggunakan RULA.

\section{HASIL DAN PEMBAHASAN}

Pelaksanaan kegiatan PkM di UMKM Cemilan Keripik Desa Kranggan Tangsel dimulai sejak 5 Februari 2020. Pada saat itu dilakukan survey ke lokasi untuk mengetahui permasalahan yang ada. Kegiatan PkM kemudian dilanjutkan dengan melakukan analisis postur kerja menggunakan RULA, perancangan stasiun kerja ergonomis, serta 
pembuatan stasiun kerja. Setelah itu dilakukan serah terima stasiun kerja pada tanggal 19 Juni 2020. Rincian kegiatan dijelaskan pada subbab berikut ini.

\section{Analisis postur kerja sebelum perbaikan menggunakan RULA}

Postur kerja yang dianalisis mencakup 3 postur yaitu mengambil pisang (gambar 2), mengiris pisang (gambar 3) dan menggoreng pisang (gambar 4).

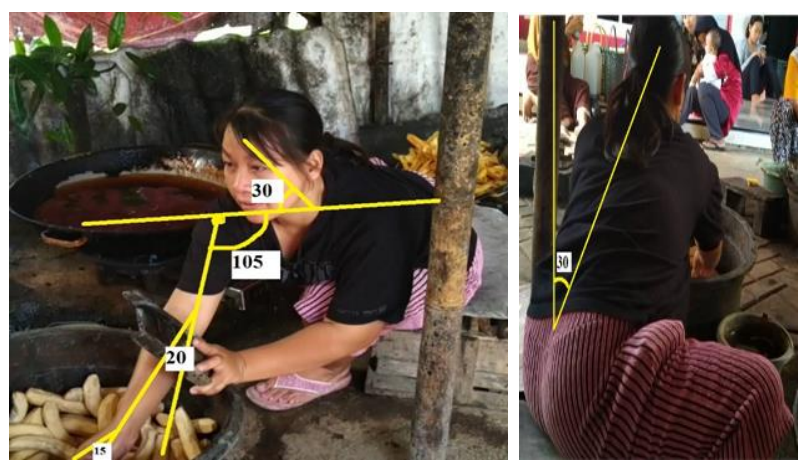

Gambar 2. Postur mengambil pisang

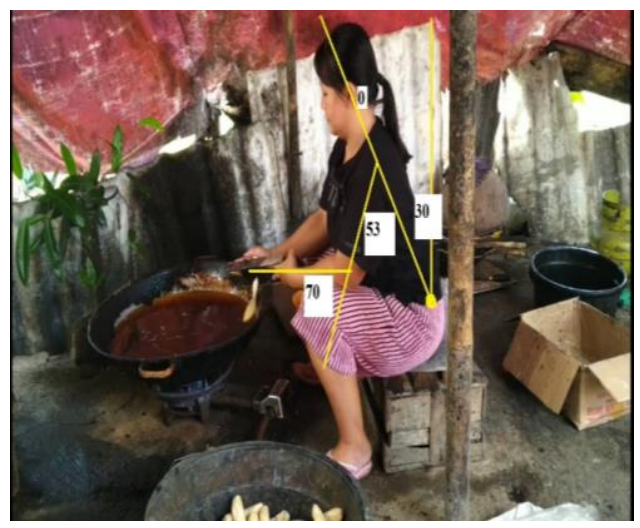

Gambar 3. Postur mengiris pisang

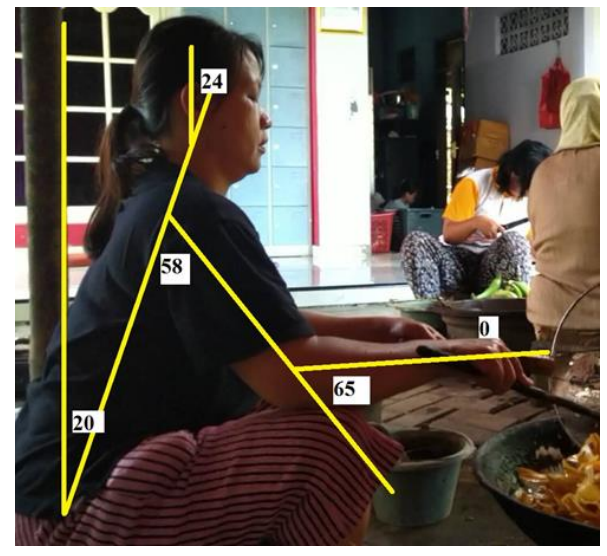

Gambar 3. Postur menggoreng pisang

Pada gambar 2-4 dapat dilihat sudut yang terbentuk antar anggota tubuh. Berdasarkan data sudut tersebut dihitung skor RULA (yang dapat dilihat secara detil pada gambar 5-7 untuk postur mengambil pisang).

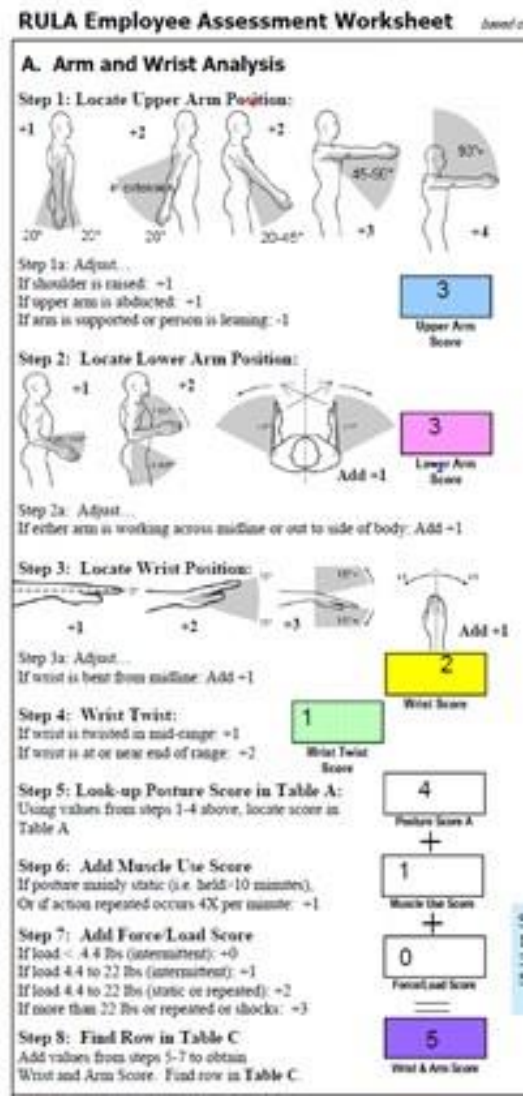


Gambar 5. Analisis RULA untuk skor lengan dan
pergelangan tangan pada postur
mengambil pisang
Dapat dilihat pada gambar 5, bahwa skor RULA untuk lengan dan pergelangan tangan pada postur mengambil pisang adalah sebesar 5. Gambar 6 menunjukkan bahwa skor leher, batang tubuh dan kaki pada postur mengambil pisang sebesar 8. Dari kedua data tersebut didapatkan data skor akhir RULA sebesar 7 (dapat dilihat pada gambar 7). Hal ini berarti postur tersebut membahayakan pekerja dan harus segera diperbaiki.

Dengan cara serupa juga dapat dianalisis postur mengiris pisang dan postur menggoreng pisang menggunakan metode RULA. Untuk postur mengiris pisang diperoleh skor akhir RULA sebesar 5, sedangkan untuk postur menggoreng pisang didapatkan skor akhir RULA sebesar 6. Jadi dari analisis RULA untuk kedua postur tersebut juga didapatkan skor RULA yang tinggi, yang berarti membahayakan pekerja. Oleh karena itu harus dilakukan perbaikan stasiun kerja.

\section{B. Neck, Trunk and Leg Analysis}

Step 9: Locate Neck Position:
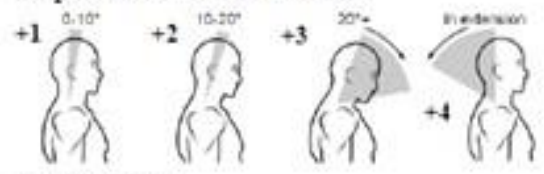

Step 9x: Adjust.

If neck is twisted: +1

If neck is side bending: +1

Step 10: Locate Trunk Position:
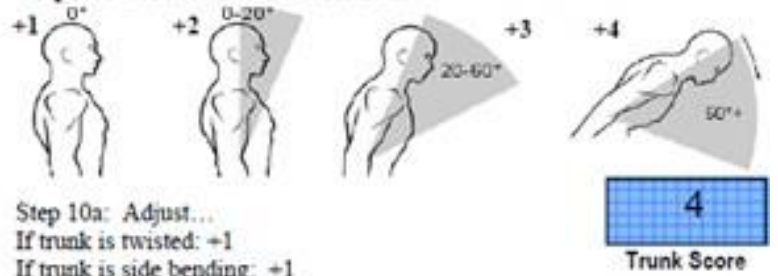

Step 10a: Adjust.

If trunk is twisted: +1

If truak is side bending: +1

Step 11: Legs:

If legs and feet are supported: +1

If not: +2

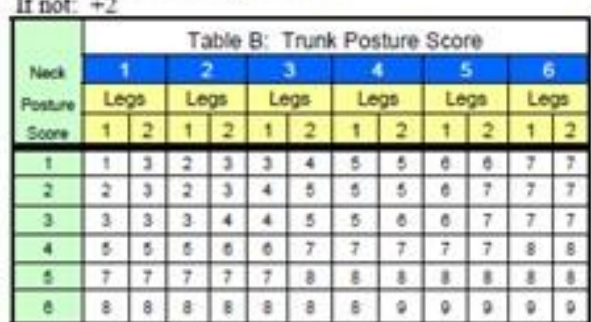

Step 12: Look-up Posture Score in Table B:

Using values from steps $9-11$ above.

locate score in Table B

Step 13: Add Muscle Use Score

If posture mainly static (i.e held 10 minutes),

Or if action repeated occurs $4 \mathrm{X}$ per minute: -1

Step 14: Add Force/Load Score

If load $<, 4,4$ tbs (intermittent) +0

If load 4.4 to 22 los (intermittent): +1

If load 4.4 to $22 \mathrm{lbs}$ (static or repeated) : +2

If more than 22 lbs or repeated or shocks: +3

Step 15: Find Column in Table C

Add values from steps 12-14 to obtain

Neck. Trunk and Leg Score. Find Column in Table C


Gambar 6. Analisis RULA untuk skor leher, batang tubuh dan kaki pada postur mengambil pisang 


\begin{tabular}{|c|c|c|c|c|c|c|c|c|}
\hline \multicolumn{9}{|c|}{ SCORES } \\
\hline \multirow{2}{*}{\multicolumn{2}{|c|}{ Table A: }} & \multirow{3}{*}{\multicolumn{2}{|c|}{$\begin{array}{l}\text { Wrist } \\
\begin{array}{c}1 \\
\text { Wist } \\
\text { Twist }\end{array}\end{array}$}} & & ure & $\mathrm{SC}$ & core & \\
\hline & & & & & \multirow{2}{*}{\multicolumn{2}{|c|}{$\begin{array}{c}3 \\
\text { Wrist } \\
\text { Twist }\end{array}$}} & \multirow{2}{*}{\multicolumn{2}{|c|}{$\mid \begin{array}{c}4 \\
\text { Wrist } \\
\text { Twist }\end{array}$}} \\
\hline Upper & Lower & & & & & & & \\
\hline & & 1 & & 12 & 1 & & 12 & 2 \\
\hline \multirow{3}{*}{1} & 1 & $1 \mid$ & & 22 & 2 & 3 & \begin{tabular}{l|l}
3 & 3 \\
\end{tabular} & \\
\hline & 2 & 2 & & \begin{tabular}{l|l}
2 & 2 \\
\end{tabular} & 3 & & & \\
\hline & 3 & 2 & & \begin{tabular}{l|l}
3 & 3 \\
\end{tabular} & 3 & 3 & \begin{tabular}{|l|l|}
4 & 4 \\
\end{tabular} & 4 \\
\hline \multirow{3}{*}{2} & 1 & 2 & $\begin{array}{ll}3 & 3 \\
3\end{array}$ & \begin{tabular}{l|l}
3 & 3 \\
\end{tabular} & 3 & 4 & & 4 \\
\hline & 2 & 3 & \begin{tabular}{l|l}
3 & 3 \\
3
\end{tabular} & \begin{tabular}{l|l}
3 & 3 \\
\end{tabular} & 3 & 4 & \begin{tabular}{|l|l}
4 & 4 \\
\end{tabular} & 4 \\
\hline & 3 & 3 & \begin{tabular}{l|l}
4.5 \\
\end{tabular} & \begin{tabular}{|l|l|}
4 & 4 \\
\end{tabular} & 4 & 4 & & 5 \\
\hline \multirow{3}{*}{3} & 1 & 3 & 36 & \begin{tabular}{|l|l|}
4 & 4 \\
\end{tabular} & 4 & 4 & \begin{tabular}{l|l}
5 & 5 \\
\end{tabular} & 5 \\
\hline & 2 & 3 & 4. & \begin{tabular}{|l|l}
4 & 4 \\
\end{tabular} & 4 & 4 & \begin{tabular}{l|l}
5 & 5
\end{tabular} & 5 \\
\hline & 3 & 4 & 4.4 & \begin{tabular}{l|l}
44 & 4 \\
\end{tabular} & 4 & 5 & & 5 \\
\hline \multirow{3}{*}{4} & 1 & 4 & 4.4 & \begin{tabular}{l|l}
44 & 4
\end{tabular} & 4 & 5 & \begin{tabular}{l|l}
5 & 5 \\
\end{tabular} & 5 \\
\hline & 2 & 4 & 4. & \begin{tabular}{l|l}
4 & 4 \\
\end{tabular} & 4 & 5 & \begin{tabular}{l|l}
5 & 5 \\
\end{tabular} & 5 \\
\hline & 3 & 4 & 4.4 & \begin{tabular}{l|l}
4 & 5 \\
\end{tabular} & 5 & 5 & & 6 \\
\hline \multirow{3}{*}{5} & 1 & 5 & 5 5: & \begin{tabular}{l|l}
5 & 5 \\
\end{tabular} & 5 & 6 & \begin{tabular}{l|l}
6 & 7 \\
\end{tabular} & 7 \\
\hline & 2 & 5 & $\begin{array}{ll}6 & 6 \\
\end{array}$ & \begin{tabular}{l|l|l}
6 & 6 \\
\end{tabular} & 6 & 7 & \begin{tabular}{l|l}
7 & 7 \\
\end{tabular} & 7 \\
\hline & 3 & 6 & \begin{tabular}{l|l}
6 & 6 \\
\end{tabular} & \begin{tabular}{l|l}
6 & 7 \\
\end{tabular} & 7 & $\begin{array}{ll}7 \\
\end{array}$ & \begin{tabular}{|l|l|}
7 & 8 \\
\end{tabular} & 8 \\
\hline \multirow{3}{*}{6} & 1 & 7 & \begin{tabular}{l|l}
7 & 7 \\
7
\end{tabular} & \begin{tabular}{l|l}
7 & 7 \\
\end{tabular} & 7 & 8 & \begin{tabular}{l|l}
8 & 9 \\
\end{tabular} & 9 \\
\hline & 2 & 8 & 8 8 8 & 88 & 8 & 9 & \begin{tabular}{l|l}
9 & 9 \\
9
\end{tabular} & 9 \\
\hline & 3 & 9 & & 99 & & 9 & & 9 \\
\hline
\end{tabular}



Scoring: (final score from Table C)

1 or $2=$ acceptable posture

3 or $4=$ further investigation, change may be needed

5 or 6 = further investigation, change soon

7 = investigate and implement change

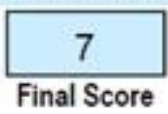

Gambar 7. Skor akhir RULA untuk postur mengambil pisang

\section{Perancangan stasiun kerja dengan metode Ulrich dan Eppinger (2012)}

Berdasarkan hasil wawancara dengan pekerja diperoleh kebutuhan akan stasiun kerja (voice of customer) sebagai berikut: stasiun kerja mudah digunakan, stasiun kerja dapat mengurangi rasa nyeri, stasiun kerja kuat dan tahan lama serta stasiun kerja ringkas. Berdasarkan $\mathrm{VoC}$ tersebut dibuat house of quality untuk mendapatkan spesifikasi teknis dari meja dan kursi kerja yang akan dibuat.

Kemudian dibuat dua alternatif rancangan stasiun kerja. Alternatif rancangan yang pertama terdiri dari meja untuk menggoreng, meja untuk meletakkan ember berisi pisang mentah, keranjang tempat meletakkan keripik pisang yang sudah jadi serta kursi kerja. Alternatif pertama ini dapat dilihat pada gambar 8 .


Gambar 8. Alternatif rancangan 1

Alternatif rancangan kedua terdiri dari meja untuk menggoreng, meja untuk meletakkan ember berisi pisang mentah, keranjang untuk produk jadi serta standing support. Gambar 9 menunjukkan alternatif rancangan kedua. Pada gambar 8 dan 9 dapat dilihat

Teknologi Tepat Guna 
perbedaan antara kedua alternatif. Stasiun kerja alternatif pertama digunakan untuk posisi kerja duduk, sedangkan alternatif kedua digunakan untuk posisi kerja berdiri.



Gambar 9. Alternatif rancangan 2

Tahap berikutnya adalah membuat stasiun kerja berdasarkan rancangan yang dipilih. Dari 2 konsep alternatif tersebut, rancangan yang dipilih oleh pengguna (pekerja) adalah konsep alternatif 1 . Produk meja dan kursi kerja dirancang sesuai dengan data antropometri pekerja. Untuk menentukan dimensi kursi digunakan data antropometri: tinggi popliteal, lebar pinggul, tinggi bahu serta panjang bokong-popliteal. Dimensi meja ditentukan menggunakan data tinggi siku duduk. Rancangan produk meja dan kursi kerja sesuai dimensi antropometri dapat dilihat pada gambar 10-12.

Gambar 10. Kursi kerja



Gambar 11. Meja untuk ember pisang mentah

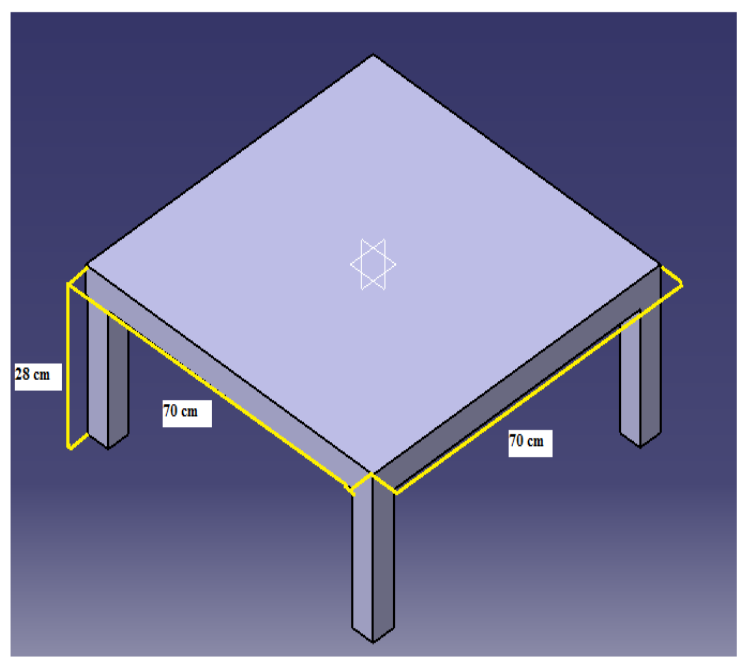

Gambar 12. Meja untuk meletakkan kuali penggorengan

Berdasarkan gambar 10-12, rancangan stasiun kerja dibuat dengan menggunakan jasa tukang las. Produk jadi yang terdiri dari 2 buah meja, 1 buah kursi dan wadah tempat kripik dapat dilihat pada gambar 13. 




Gambar 13. Stasiun kerja yang sudah dibuat

Kemudian dilakukan uji coba/simulasi postur kerja (gambar 14-16) dengan stasiun kerja yang baru. Selanjutnya dilakukan analisis postur kerja yang baru dengan menggunakan metode RULA. Hasil analisis RULA untuk ketiga postur tersebut dapat dilihat pada tabel 1. Skor akhir RULA untuk ketiga postur kerja tersebut adalah 3, sehingga dapat disimpulkan bahwa stasiun kerja yang baru dapat mengurangi risiko bahaya musculoskeletal pada pekerja.

Tabel 1. Hasil Analisis RULA untuk ketiga postur kerja yang baru

\begin{tabular}{lccc}
\hline postur & $\begin{array}{c}\text { Skor lengan } \\
\text { dan } \\
\text { pergelangan } \\
\text { tangan }\end{array}$ & $\begin{array}{c}\text { Skor } \\
\text { leher, } \\
\text { batang } \\
\text { tubuh dan } \\
\text { kaki }\end{array}$ & $\begin{array}{c}\text { Skor akhir } \\
\text { RULA }\end{array}$ \\
\hline $\begin{array}{l}\text { Mengambil } \\
\text { pisang }\end{array}$ & 4 & 2 & 3 \\
$\begin{array}{l}\text { Mengiris } \\
\text { pisang }\end{array}$ & 3 & 2 & 3 \\
$\begin{array}{l}\text { Menggoreng } \\
\text { pisang }\end{array}$ & 3 & 2 & 3 \\
\hline
\end{tabular}

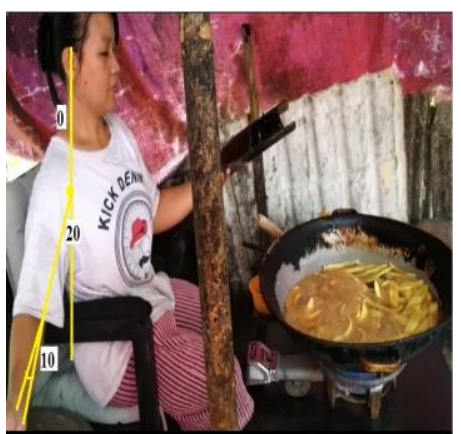

Gambar 14. Postur mengambil pisang menggunakan stasiun kerja baru

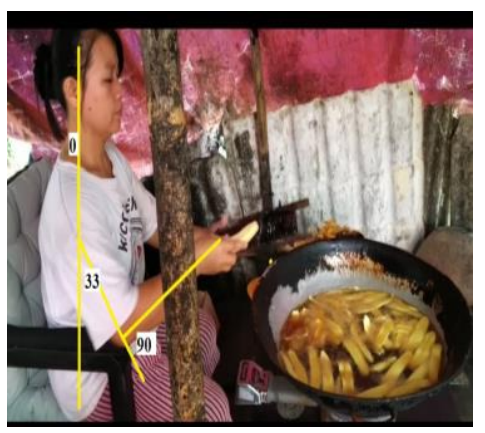

Gambar 15. Postur mengiris pisang menggunakan stasiun kerja yang baru

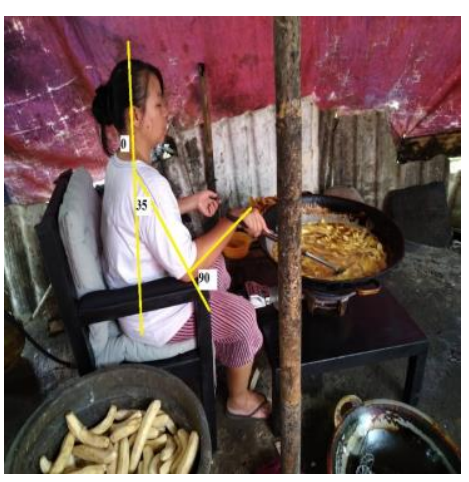

Gambar16. Postur menggoreng menggunakan stasiun kerja yang baru

Setelah dilakukan serah terima, beberapa minggu kemudian dilakukan wawancara dengan pekerja. Hasil wawancara menunjukkan bahwa stasiun kerja yang dibuat bermanfaat karena pekerja dapat bekerja dengan lebih nyaman. Untuk

Teknologi Tepat Guna 
keberlanjutan kegiatan PkM di UMKM ini perlu dipertimbangkan untuk melakukan perbaikan stasiun kerja di bagian yang lain, seperti bagian pengemasan. Saat ini pekerja bagian pengemasan melakukan pekerjaannya sambil duduk di lantai. Selain postur kerja yang tidak ergonomis, juga terdapat masalah higienitas produk yang dikemas. Oleh karena itu dirasa perlu untuk dilakukan perbaikan yang berkelanjutan di UMKM Cemilan Keripik ini.

\section{KESIMPULAN}

Kegiatan PkM ini telah berlangsung dengan baik, dimana telah dibuat dan diserahkan meja dan kursi ergonomis untuk bagian penggorengan keripik. Berdasarkan hasil analisis RULA, diketahui bahwa dengan adanya stasiun kerja baru tersebut, skor RULA turun dari 7 menjadi 3 untuk postur mengambil pisang, dari 5 menjadi 3 untuk postur mengiris pisang, dan turun dari 6 menjadi 3 untuk postur menggoreng pisang. Hal ini berarti dengan adanya meja dan kursi tersebut, risiko cedera yang dialami pekerja juga turun. Setelah dilakukan wawancara dengan pekerja, juga diketahui bahwa stasiun kerja yang dibuat bermanfaat karena pekerja dapat bekerja dengan lebih nyaman. Untuk keberlanjutan kegiatan PkM di UMKM ini perlu dipertimbangkan untuk melakukan perbaikan stasiun kerja di bagian yang lain, seperti di bagian pengemasan. Hal ini disebabkan karena proses pengemasan masih dilakukan sambil duduk di lantai.

\section{UCAPAN TERIMAKASIH}

Ucapan terimakasih disampaikan kepada LPPM UPH yang telah mendukung pelaksanaan kegiatan PkM No. PM-008/FaST///2020.

\section{REFERENSI}

Bintang, A. \& Dewi, S. (2017). Analisa Postur Kerja Menggunakan Metode OWAS dan RULA. Jurnal Teknik Industri. 18(43): 43-54.

Chuan, T.K, Hartono, M. dan Kumar, N. (2010). Anthropometry of the Singaporean and Indonesian Populations. International Journal of Industrial Ergonomics 40:757-
766.

Christiani, A., Ishak, Rahayu, P.C, Suprapto, A.N dan Kevin (2019). Pembuatan Stasiun Kerja dan Alat Bantu untuk Proses Pelubangan dan Pengepresan pada Industri Rumahan di Desa Kedung Dalem, Pasar Kemis, Tangerang. Journal of Industrial Manufacturing, 4(1):117-134.

Dzikrillah, N. dan Yuliani, E. N. S. (2015). Analisis Postur Kerja Menggunakan Metode Rapid Upper Limb Assessment (RULA) Studi Kasus PT. TJ Forge Indonesia. Jurnal Ilmiah Teknik Industri . 3 (3): 150 - 155.

McAtamney, L. dan Corlett, E. N. (1993). RULA: a survey method for the investigation of workrelated upper limb disorders. Applied Ergonomics 24(2):91-99.

McCauley Bush, P. (2011) Ergonomics: Foundational Principles, Applications and Technologies, an Ergonomics Textbook; CRC Press, Taylor \& Francis, Boca Raton, FL.

Nunes, I. \& McCauley Bush, P. (2012). WorkRelated Musculoskeletal Disorders Assessment and Prevention. Ergonomics: A System Approach 10.5772/37229.

Shrivastava, P. (2016). House of Quality: An Effective Approach to Achieve Customer Satisfaction \& Business Growth in Industries. International Journal of Science and Research, 5(9):1366-1371.

Ulrich, K. T., dan Eppinger, S.D. (2012). Product Design and Development. 5th Edition. New York:McGraw-Hill.

Wijaya, I. S. A. dan Muhsin, A. (2018). Analisa Postur Kerja dengan Metode Rapid Upper Limb Assessment (RULA) pada Oparator Mesin Extruder di Stasiun Kerja Extruding pada PT XYZ. Jurnal OPSI (Optimasi Sistem Industri) 11 (1) :49-57

Teknologi Tepat Guna 261 
Prosiding PKM-CSR, Vol. 2 (2019)

e-ISSN: 2655-3570 